\title{
Trajectories of allostatic load among older Americans and Britons: longitudinal cohort studies
}

\author{
Gindo Tampubolon ${ }^{1 *}$ (D) and Asri Maharani ${ }^{2}$
}

\begin{abstract}
Background: Difference in life expectancy between males and females has been suggested to rest on sex difference in physiological dysregulation. But allostatic load, a physiological index, has not been carefully examined for an extended period beyond middle age. We aim to draw longitudinal trajectories of allostatic load in a national sample of older Americans and Britons; also to examine sex-based trajectories and factors behind their differences.

Methods: We studied men and women aged $\geq 50$ years participating in the Health and Retirement Study Waves 8 11, 2006-2012 ( $N=15,583$ person-years) and the English Longitudinal Study of Ageing Waves 2, 4 and 6, 2004-2012 ( $N=14,765$ person-years). Because of the difference in provenance, we included different number of biomarkers to calculate allostatic load in HRS and ELSA. In HRS we used 8 biomarkers (systolic and diastolic blood pressure, haemoglobin A1c, high-density lipoprotein, total cholesterol, waist circumference, cystatin C, and C-reactive protein) , while ELSA allostatic load was constructed from 10 biomarkers (systolic and diastolic blood pressure, haemoglobin A1c, high-density lipoprotein, total cholesterol, waist circumference, BMI, triglyceride, fibrinogen and C-reactive protein). A growth curve model was fitted to repeated observations of allostatic load, demographic characteristics, socioeconomic position, comorbidities and health behaviours (smoking, drinking, and physical exercise). To account for attrition, a joint model was applied.
\end{abstract}

Results: The analysis showed that allostatic load increases linearly with age in the U.S. However, there are different levels for males and females. In England allostatic load follows such different paths that their trajectories cross in later life.

Conclusions: Sex-based trajectories of allostatic load showed distinct female advantage and are mostly consistent with female advantage in life expectancy.

Keywords: Allostatic load, Ageing, Longitudinal analysis, Attrition

\section{Background}

The increasing proportion of older people in the population and their increasing life expectancy give larger number of older people longer lives [1]. This prospect raises the challenge of ensuring that the bulk of their lives is lived in a state of good health, free of morbidity and frailty, that will facilitate their continuing contributions to society, polity and the economy. Between the sexes, however, life expectancy differs with an advantage to females. Both in the US and the

\footnotetext{
* Correspondence: tampubolon@manchester.ac.uk

${ }^{1}$ Sociology and Cathie Marsh Institute for Social Research, University of Manchester, Humanities Bridgeford Street Building, Oxford Road, Manchester M13 9PL, UK

Full list of author information is available at the end of the article
}

UK, government actuaries listed different life expectancies at various ages for males and females, with higher values for females. This advantage narrows down with age; thus sex difference in life expectancy converges with age $[2,3]$.

Despite the female advantage in life expectancy, they have higher morbidity rates and a declined quality of life than males in later life [4]. Literature has reported lower performance of older women on balance and gait tasks than men [5-7]. Older women also had higher prevalence of falling $[8,9]$ and the incidence of physical ability $[10,11]$ than their male counterparts. Sex differences in body composition, physical activity, and aerobic fitness are among the

(c) The Author(s). 2018 Open Access This article is distributed under the terms of the Creative Commons Attribution 4.0 International License (http://creativecommons.org/licenses/by/4.0/), which permits unrestricted use, distribution, and 
plausible explanations of these differences. Prior studies found that female respondents reported less habitual physical activity and had lower cardiorespiratory fitness than male respondents [12, 13], which may result in have greater adiposity and less lean mass among older women [14]. The paradoxical differences physical health among males and females may also related to underlying physiological dysregulation, particularly allostatic load [15]. Yang and Kozloski reported that allostatic load is higher for females throughout adulthood (17+ years), showing a female disadvantage in allostatic load. The female advantage in life expectancy sits uneasily with female disadvantage in allostatic load.

Allostatic load captures the notion that the human physiological system is not a fixed and stable system but a dynamically stable one, especially in the face of insults, hazards and injuries to various organ systems [16-21]. Allostatic load is the physiological wear and tear that the body sustains throughout the life course. Allostatic load has been found to longitudinally predict self-rated health, physical function, frailty and ultimately mortality in the US and UK $[22,23]$. It also shows gradients along markers of socioeconomic position [23]. Allostatic load is therefore useful not only as a risk factor for morbidity, frailty and mortality, but also in understanding the mechanism of ageing throughout the life course [22].

Few studies have been devoted to uncovering the longitudinal pattern of allostatic load based on repeated measurements. As to socioeconomic gradient in allostatic load, what role the gradient plays in longitudinal change remains relatively uncharted. When examining longitudinal patterns of allostatic load in later life, a study must also contend with the problem of attrition: i.e. when participants are lost to follow up for various reasons, some to do with health and death. This attrition problem is pervasive in ageing studies [24], and to deal with this various models have been applied [25-29], including joint model as applied to the English Longitudinal Study of Ageing [25, 26].

To focus our efforts four questions will be answered. First, is there a sex difference in longitudinal trajectories of allostatic load? Second, given the female advantage in life expectancy, do these trajectories show a female advantage, i.e. a lower allostatic load trajectory for females? Third, given that psychosocial factors get under the skin and affect physiological regulation $[20,30,31]$, what social factors are linked with the trajectories? Lastly, are there any differences between the two countries?

This work makes three contributions. It is the first to draw longitudinal trajectories of allostatic load for males and females based on the major study of ageing in America and Britain. Second, in drawing these trajectories, it has uncovered unique patterns that are consistent with the female advantage in life expectancy. Lastly, it showed perceptibly advantageous trajectories of allostatic load in older Americans consistent with emerging comparative research [32-34].

\section{Methods}

We used two nationally longitudinal studies of aging: the U.S. Health and Retirement Study (HRS) [35] and The English Longitudinal Study of Ageing (ELSA) [36]. HRS is a multinational biannual household panel survey that collects information on the demographic characteristics, socioeconomic position, comorbidities and health behaviours of individuals aged $50+$ in the U.S., while ELSA provided similar information among individuals in the same age range in England. HRS study was started in 1992, while the first wave of ELSA data was collected in 2002. So far there are twelve and seven waves of HRS and ELSA, respectively. This study used waves 8 to 11 of HRS (20062012) and every even-numbered wave (2004, 2008 and 2012/2013) of ELSA as the biomarker information was collected in those waves.

\section{Dependent variable}

Due to the availability of the data, we included different numbers of biomarkers in HRS and ELSA. Eight biomarkers (systolic and diastolic blood pressure, haemoglobin A1c, high-density lipoprotein/total cholesterol, waist circumference, cystatin $\mathrm{C}$, and $\mathrm{C}$-reactive protein) in the HRS and ten biomarkers (systolic and diastolic blood pressure, haemoglobin A1c, high-density lipoprotein/total cholesterol, waist circumference, BMI, triglyceride, fibrinogen and C-reactive protein) in the ELSA were included in the analysis. Following Stephan et al. (2016) [37], we calculated allostatic load scores in HRS and ELSA in two stages. Firstly, we standardised each of the marker scores to have a mean of zero and a standard deviation of one. Secondly, we took the average of those standardised scores, resulting in a summary allostatic load scores that can be interpreted in terms of standard deviation units. Higher values indicate higher multisystem physiological dysregulation.

\section{Covariates}

Demographic covariates include sex and age. Since age is capped at 90 in ELSA, information from respondents aged 50 to 89 in both surveys was used. Like other health functions, allostatic load is also shaped by social determinants of health. These include wealth tertiles (top, middle and bottom as reference), education (some college and high school or less as reference), and marital status (married/cohabiting and other as reference) $[25,38,39]$. 
Based on positive medical history (self-report of 'has been diagnosed by professionals'), a sum of indicators about comorbidities were included, covering diabetes, cancer, hypertension, lung disease, heart condition, and stroke. Behavioural risk factors known to be important in other studies include smoking (current smoker versus not current smoker as reference), drinking (days in a week having a drink) and physical activity (rigorous, moderate and mild or less as reference) [40].

We included only observation of respondents with complete information on the allostatic load components and the covariates in HRS ( $N=15,583$ observations) and ELSA ( $N=14,765$ observations) in the analysis. Differences between those included and left out were tested using $t$-test (continuous variables) or $\chi^{2}$ test (categorical variables). At baseline, compared to those left out the analytic sample is younger (67 versus 73 year, $p<0.001$ in the U.S and 65 versus 67 year, $p<0.001$ in England), has fewer women $(50 \%$ versus $57 \%$; $p<0.001$ in the U.S. and $53 \%$ versus 54\%; $p=0.338$ in England), and has lower levels of allostatic load $(-0.01$ versus $0.008, p=$ 0.039 in the U.S. and 1.8 versus 2, $p<0.001$ in England).

\section{Statistical analysis}

To model how allostatic load changes over time using repeated observations, a growth curve model with random intercepts is applied. This model gives consistent estimates of the effects of risk factors when some participants are lost in subsequent visits, assuming attrition at random. We fit two models to address the questions above. First the main allostatic model built one trajectory for both sexes. Second, to check whether there is a difference in the rate of change between the sexes, the interaction model has an additional sex-age interaction term. To deal with attrition bias, a joint model is used $[24,26,27,41]$. This model has recovered robust estimates of cognitive ageing in Australia [27], quality of life and cognition among older adults in England [25, 26]. We used the joint model to deal with the attrition in the longitudinal study. The random effects $(h($.$) below) in$ the joint model influence both allostatic load, $y$, and attrition, $t$, given these, allostatic load and attrition are independent. A joint model has two parts: the growth curve model $(f($.) below) and the survival model $(g($.) below)with gender, age polynomial of degree three and the random intercepts from the first partt $[25,26]$.

$$
L=\int f\left(y_{i} \mid b_{i}, x_{i}\right) g\left(t_{i} \mid b_{i}, x_{i}\right) h\left(b_{i}\right) d b_{i}
$$

We compare the results of growth curve models with those of joint or attrition-corrected models. The analyses were done in Stata 14 (StataCorp LP, College Station, Texas) and Latent Gold Syntax 5.1.
We carried out three supplementary analyses to check the robustness of our results. In the first supplementary analysis, we followed Read and Grundy (2014) by computing allostatic load score in ELSA using 13 indicators of whether biomarker values fell into their high risk quartiles [23]. The indicators cover five organ systems, including cardiovascular (diastolic blood pressure, systolic blood pressure), inflammation (CRP and fibrinogen), metabolic (haemoglobin A1c, high-density lipoprotein/total cholesterol ratio, triglycerides, and fasting glucose), body fat (BMI, waist circumference), and respiratory systems (forced expiratory volume, forced vital capacity and passive expired volume). Within each organ system each indicator receives the same proportion, for example the inflammation system has two biomarkers, each potentially contributing half a point when the biomarker value is found in the high risk quartile (zero otherwise) [22, 23]. The threshold of the high risk quartile is replaced with a clinical cut-off when there is one, for example the cut-off for male waist circumference is $102 \mathrm{~cm}$. Finally, medication was considered, so that the value is automatically considered as high risk if the participant is using medication. The medication includes blood pressure lowering medication, anticoagulants, lipid lowering medication, diabetes medication and lung function medication. The scores range from 0 to 5 .

In the second supplementary analyses, we analysed only the post-war cohort (those who were born on 1946 onwards) of ELSA to examine the effect of cohort on the allostatic load. Our previous work found that the trajectories of depressive symptoms between cohorts (pre-war, war, and post-war cohorts) in the US and England took different shapes [32]. The trajectories of pre-war cohorts in both countries and war cohort in England took a U-shape, while those of war cohort in England and post-war cohorts in both countries followed an inverted U-shape. We thus hypothesised that the allostatic load trajectory of the post-war cohort in ELSA follows that in HRS. In the final sensitivity analysis, we included the relevant medications taken by the respondents (medications for hypertension, hyperlipidaemia, and diabetes mellitus in ELSA and medication prescribed by the health professionals in HRS), and height (in $\mathrm{cm}$ ).

\section{Results}

The sample for analysis consists of $56 \%$ and $54 \%$ females in HRS and ELSA data, respectively (Table 1). The table also contains distribution across age groups, only for description and not for modelling, which shows that for either males or females there is an increasing age gradient in allostatic load in both data. In particular it shows that before 70 years in ELSA 
Table 1 Descriptive summaries of allostatic load scores (means) in different groups

\begin{tabular}{|c|c|c|c|c|c|c|c|c|}
\hline & \multicolumn{4}{|l|}{ HRS } & \multicolumn{4}{|l|}{ ELSA } \\
\hline & $\bar{N}$ & $\begin{array}{l}\text { All } \\
N=15,583\end{array}$ & $\begin{array}{l}\text { Male } \\
N=6787\end{array}$ & $\begin{array}{l}\text { Female } \\
N=8796\end{array}$ & $\bar{N}$ & $\begin{array}{l}\text { All } \\
N=14,765\end{array}$ & $\begin{array}{l}\text { Male } \\
N=6721\end{array}$ & $\begin{array}{l}\text { Female } \\
N=8044\end{array}$ \\
\hline All & & 0.006 & 0.027 & -0.009 & & 1.926 & 1.92 & 1.932 \\
\hline \multicolumn{9}{|l|}{ Age group } \\
\hline $50-$ & 3752 & -0.044 & 0.006 & -0.084 & 4109 & 1.554 & 1.592 & 1.523 \\
\hline $60-$ & 4532 & -0.002 & 0.025 & -0.023 & 5843 & 1.834 & 1.850 & 1.821 \\
\hline $70-$ & 4735 & 0.028 & 0.035 & 0.023 & 3648 & 2.255 & 2.210 & 2.291 \\
\hline 80- & 2564 & 0.056 & 0.047 & 0.064 & 1165 & 2.676 & 2.553 & 2.771 \\
\hline \multicolumn{9}{|l|}{ Married/cohabit } \\
\hline Not married & 4753 & 0.047 & 0.067 & 0.04 & 4555 & 2.116 & 2.07 & 2.139 \\
\hline Married & 10,830 & -0.011 & 0.017 & -0.041 & 10,210 & 1.842 & 1.876 & 1.807 \\
\hline \multicolumn{9}{|l|}{ Wealth tertiles } \\
\hline Poorest & 4891 & 0.069 & 0.098 & 0.049 & 4135 & 2.251 & 2.198 & 2.289 \\
\hline Middle & 5303 & 0.001 & 0.024 & -0.016 & 5089 & 1.97 & 1.968 & 1.971 \\
\hline Wealthiest & 5389 & -0.045 & -0.025 & -0.062 & 5541 & 1.645 & 1.696 & 1.598 \\
\hline \multicolumn{9}{|l|}{ Education } \\
\hline$<$ High school & 2569 & 0.077 & 0.087 & 0.069 & 4561 & 2.252 & 2.249 & 2.254 \\
\hline High school & 5080 & 0.029 & 0.059 & 0.011 & 5692 & 1.884 & 1.922 & 1.855 \\
\hline Some college & 7934 & -0.031 & -0.007 & -0.051 & 4512 & 1.651 & 1.692 & 1.6 \\
\hline \multicolumn{9}{|l|}{ Num. comorbidities } \\
\hline 0 & 4160 & -0.121 & -0.086 & -0.143 & 6401 & 1.304 & 1.306 & 1.302 \\
\hline 1 & 5270 & -0.000 & 0.011 & -0.009 & 5667 & 2.247 & 2.238 & 2.254 \\
\hline 2 & 3671 & 0.065 & 0.074 & 0.057 & 2016 & 3.044 & 2.634 & 2.585 \\
\hline $3+$ & 2482 & 0.148 & 0.136 & 0.161 & 681 & 3.193 & 3.202 & 3.187 \\
\hline \multicolumn{9}{|l|}{ Current smoker } \\
\hline No & 13,611 & 0.006 & 0.024 & -0.007 & 12,979 & 1.902 & 1.889 & 1.912 \\
\hline Yes & 1972 & 0.009 & 0.049 & -0.022 & 1786 & 2.107 & 2.147 & 2.074 \\
\hline \multicolumn{9}{|l|}{ Drinking } \\
\hline Less & 14,001 & 0.008 & 0.031 & -0.008 & 9098 & 2.057 & 2.054 & 2.059 \\
\hline Daily & 1582 & -0.007 & 0.001 & -0.021 & 5667 & 1.716 & 1.763 & 1.66 \\
\hline \multicolumn{9}{|c|}{ Vigorous physical activity } \\
\hline No & 9994 & 0.042 & 0.07 & 0.024 & 12,026 & 2.027 & 2.037 & 2.02 \\
\hline Yes & 5589 & -0.057 & -0.03 & -0.086 & 2739 & 1.483 & 1.51 & 1.451 \\
\hline
\end{tabular}

and before 80 years in HRS, females have lower allostatic load than males, but beyond this age the order changes. So although both sexes appear to have comparable levels of allostatic load, its age distribution is quite different in the two sexes.

Married, better-educated and wealthy participants have lower allostatic load compared to reference categories in both data. Lastly (bottom block), to pick one behavioural factor, more physical activity inversely associates with allostatic load.

Table 2 collects the results of the growth curve and joint models using HRS and ELSA. The first model, labelled
Main, showed that allostatic load increases with age in HRS $(\beta=0.003, p<0.001)$, and ELSA $(0.002, p<0.001)$. To check for different trajectories for females and males, a sex-age interaction term was added in the Interaction model. This model gave the interaction terms positive and significant coefficients in both data, suggesting the trajectories are significantly different for females and for males.

To ease interpretation and comparison, the coefficients for the two joint models are plotted together in a figure of two panes corresponding to the two models (Fig. 1 for HRS and Fig. 2 for ELSA). Being female is associated with lower allostatic score in all 
Table 2 Models of age trajectories of allostatic load, coefficients and standard errors: main and interaction models. Source HRS wave 8-11 (2006-2012) and ELSA Wave 2, 4 and 6 (2004-2012)

\begin{tabular}{|c|c|c|c|c|}
\hline & \multicolumn{2}{|l|}{ HRS } & \multicolumn{2}{|l|}{$E L S A$} \\
\hline & Main & Interaction & Main & Interaction \\
\hline Age & $0.003 \pm 0.000^{* * *}$ & $0.001 \pm 0.000^{* * *}$ & $0.002 \pm 0.000^{* * *}$ & $-0.0001 \pm 0.000$ \\
\hline Sex, Female & $-0.104 \pm 0.007^{* * *}$ & $-0.251 \pm 0.047^{* * *}$ & $-0.093 \pm 0.009^{* * *}$ & $-0.376 \pm 0.062^{* * *}$ \\
\hline Age $^{*}$ gender & & $0.002 \pm 0.000^{* * *}$ & & $0.004 \pm 0.000^{* * *}$ \\
\hline Married/cohabit & $-0.023 \pm 0.008^{* * *}$ & $-0.019 \pm 0.008^{* *}$ & $-0.007 \pm 0.009$ & $-0.002 \pm 0.009$ \\
\hline Middle wealth & $-0.042 \pm 0.008^{* * *}$ & $-0.042 \pm 0.008^{* * *}$ & $-0.043 \pm 0.008^{* * *}$ & $-0.043 \pm 0.008^{* * *}$ \\
\hline Wealthiest & $-0.068 \pm 0.009^{* * *}$ & $-0.067 \pm 0.009^{* * *}$ & $-0.091 \pm 0.009^{* * *}$ & $-0.090 \pm 0.009^{* * *}$ \\
\hline High school & $-0.006 \pm 0.011$ & $-0.007 \pm 0.011$ & $-0.056 \pm 0.011^{* * *}$ & $-0.053 \pm 0.011^{* * *}$ \\
\hline Some college & $-0.047 \pm 0.01^{* * *}$ & $-0.048 \pm 0.01^{* * *}$ & $-0.102 \pm 0.012^{* * *}$ & $-0.101 \pm 0.012^{* * *}$ \\
\hline Num. comorbidities & $0.093 \pm 0.003^{* * *}$ & $0.093 \pm 0.003^{* * *}$ & $0.033 \pm 0.003^{* * *}$ & $-0.043 \pm 0.008^{* * *}$ \\
\hline Current smoker & $-0.032 \pm 0.011^{* * *}$ & $-0.031 \pm 0.011^{* * *}$ & $-0.011 \pm 0.013$ & $-0.011 \pm 0.013$ \\
\hline Past smoker & $0.006 \pm 0.007$ & $0.008 \pm 0.007$ & $0.089 \pm 0.014^{* * *}$ & $0.088 \pm 0.014^{* * *}$ \\
\hline Drink $>5$ days/week & $-0.008 \pm 0.011$ & $-0.008 \pm 0.011$ & $-0.021 \pm 0.007^{* * *}$ & $-0.021 \pm 0.007^{* * *}$ \\
\hline Vigorous exercise & $-0.076 \pm 0.007^{* * *}$ & $-0.076 \pm 0.007^{* * *}$ & $-0.044 \pm 0.008^{* * *}$ & $-0.044 \pm 0.008^{* * *}$ \\
\hline Constant & $-0.159 \pm 0.03^{* *}$ & $-0.079 \pm 0.039^{* *}$ & $-0.001 \pm 0.038$ & $0.147 \pm 0.050^{* * *}$ \\
\hline
\end{tabular}

Note: Sig.: ${ }^{*}=10 \%$ or less; ${ }^{* *}=5 \%$ or less; ${ }^{* * *}=1 \%$ or less

models. The positive and significant coefficient for age and its interaction terms suggest different trajectories for females and for males. Other coefficients are not so different in the two survey data. Being wealthy and having high educational attainment have inverse relationships with allostatic score. The comorbidities and behavioural covariates (bottom block) also show similar patterns: comorbidities associate positively with allostatic load while rigorous physical exercise strongly associates with lower allostatic load.
Given that an extensive set of covariates is controlled, a summary of the trajectories based on the predicted allostatic load from the joint models can be drawn (Fig. 3). Comparing HRS (left) and ELSA (right) highlights striking similarities and differences. Older people on the west and east sides of the Atlantic accumulates allostatic load in a linear fashion as they age. In the US, females have lower allostatic load throughout later life, consistent with female advantage in life expectancy. A similar pattern characterises Britain although there is a

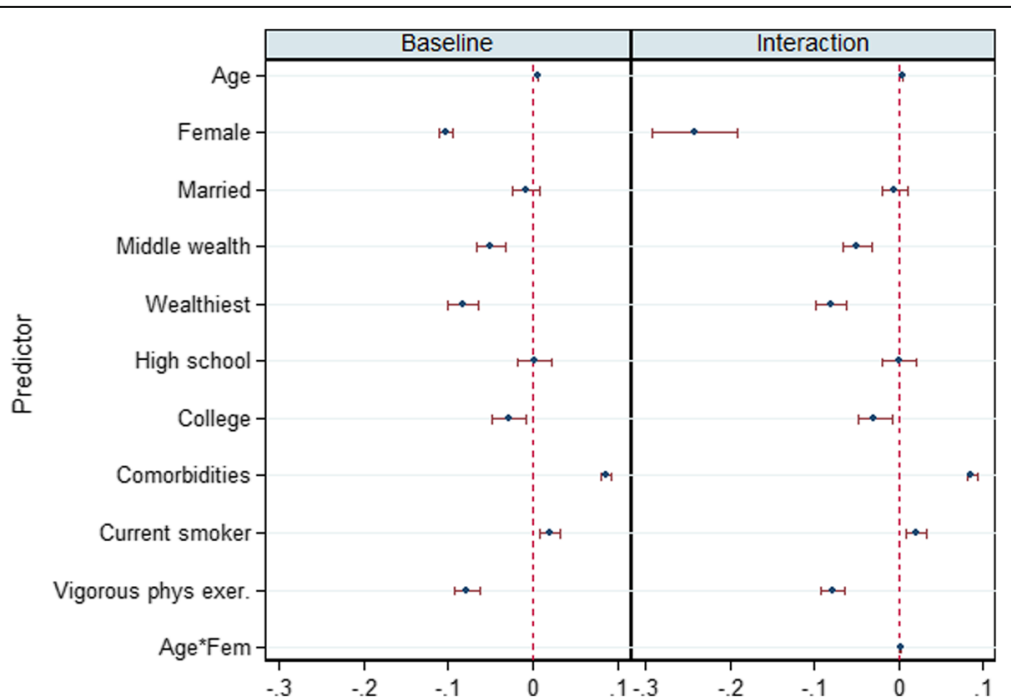

Fig. 1 Attrition corrected models of age trajectories of allostatic load, coefficients and 95\% confidence intervals: Main Allostatic and Sex interaction models. Source HRS 2004-2013 


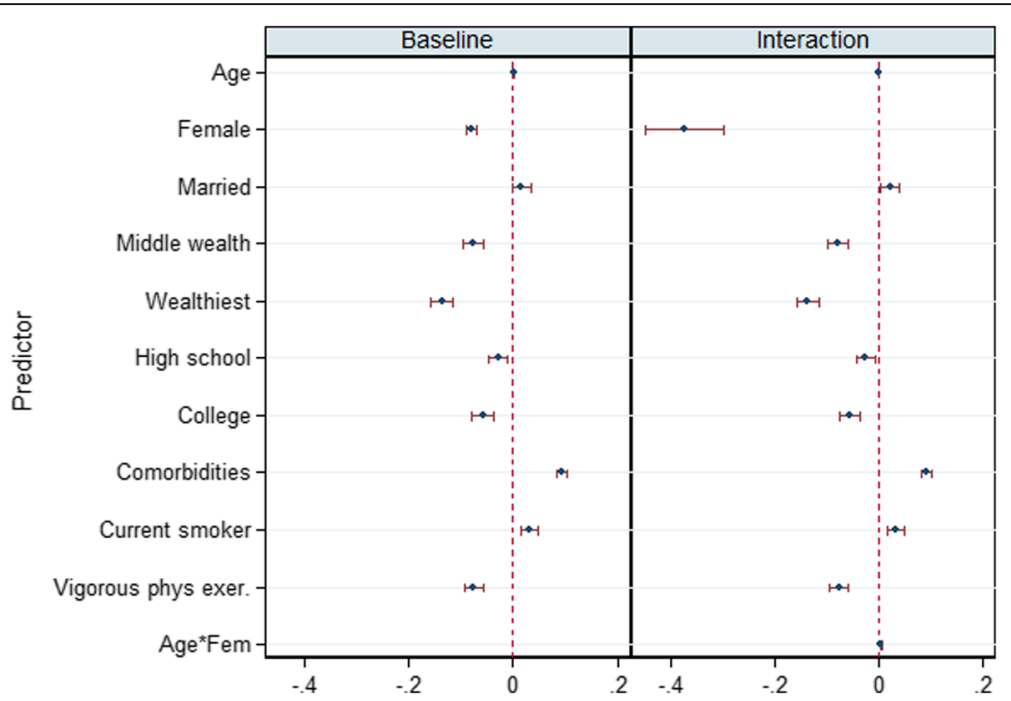

Fig. 2 Attrition corrected models of age trajectories of allostatic load, coefficients and 95\% confidence intervals: Main Allostatic and Sex interaction models. Source ELSA 2004-2013

crossover in the latter half when female advantage disappeared. Nonetheless, the sex difference throughout later life is slight and unlikely to be a clinically significant dysregulation [42]. Particularly the sex difference in Britain is negligible compared to that in America. Similar trajectories are found in our supplementary analyses using ELSA data. Being female is associated with lower allostatic load $(\beta=-0.451, p<0.001)$ (see Appendix 1), we find a crossover of the allostatic load trajectories of males and females in the age of $57(\beta=0.005, p<0.001)$ in which the allostatic load of the males is higher than that of females afterwards (see Appendix 2). The effect of cohort was shown in our analysis including only the post-war cohort of ELSA (see the Appendix 3). Supporting our previous work [32], the allostatic load trajectories of the post-war cohort of ELSA followed those of
HRS: females have lower allostatic load throughout later life. The final sensitivity analysis demonstrated that the relationships between gender and allostatic load remained significant after controlling by height and the relevant medication (see Appendix 4). This sensitivity analysis shows that the results are robust.

\section{Discussion}

We set out to draw the sex-based trajectories of allostatic load in samples representing the American and British older populations. Upward trajectories of allostatic load for both males and females are found, but the rates of change differ for the two sexes. This led to allostatic load incline among older Americans and additionally a cross-over in older British allostatic load trajectories at the mid-60s. Allostatic load trajectory as a
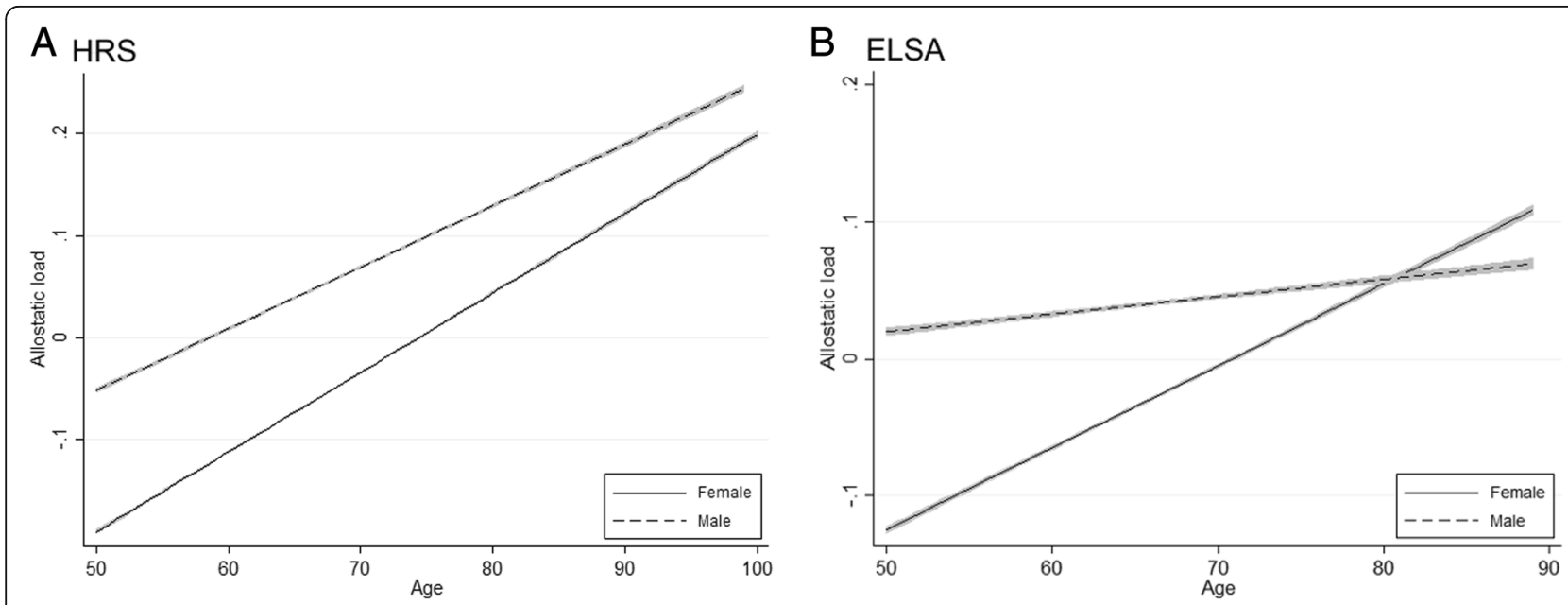

Fig. 3 Predicted trajectories of allostatic load for females and males. Source HRS 2004-2013 and ELSA 2004-2013 
physiological signature of ageing unfolds differently for males and females. This is a novel finding that deserves replication and reflection, some of which are offered later.

The patterns in America, i.e. linear accumulation and female advantage, are consistent with the patterns of life expectancy worldwide. These patterns also showed a gentler incline of allostatic load overtime, compared to those in Britain. The somewhat advantageous patterns revealed in America is consistent with recent evidence uncovered using the HRS and ELSA. Tampubolon and Maharani [32] showed that today older Americans are composed of sociohistorical cohorts (pre-war, war and post-war) that have an advantageous mental health. The majority (war and post-war cohorts) have advantageous trajectory depression in later life. Not so in older Britons: only the post-war cohort attains this advantage (ibid, Fig. 1). A larger proportion of older Americans than older Britons has a better mental health trajectory. Consistent with this, the HRS patterns on the left pane of Fig. 3 and the post-war cohort patterns on the Appendix 3 suggest a lower allostatic load trajectory among female than male at any age.

This study has a number of limitations. Direct measures of the stress response system such as urinary norepinephrine, epinephrine and salivary cortisol are not available. Including these is wholly desirable [18] but would no doubt be challenging. These older adult participants have given many physical and blood measurements over the years; therefore this study and others on allostatic load [23, 37] have tried to make the most of what the participants have already contributed. Another limitation is the handling of attrition. The joint model is only one solution; two other alternatives are pattern mixture model and selection models [24, 28]. Accounting for attrition with these alternatives is worth considering. Finally, one limitation of large samples is that the beta weights are very low, but the $p$ values are statistically significant. Although there is a statistically significant change, the change is not strong.

An advantage of this study is the nationally representative nature of both HRS and ELSA, ensuring that the accumulation of physiological wear and tear in these populations can be uncovered without being unduly influenced by specific patterns in some clinical or patient samples. Another strength arises from its longitudinal design, with repeated measures not only of allostatic load but also of an extensive set of covariates.

The similar increase of allostatic load found among older Americans and older Britons stands in contrast with the trajectories found in American adults [15]. There the pattern is of female disadvantage and of divergence: females carry heavier allostatic load throughout adulthood and the difference continues to widen with age. The pattern was derived from cross-sectional data, and this may explain the contrast, since cross-sectional design has been found to give overestimates of changes in health functioning [43].

The socio-economic gradient in trajectories of allostatic load found here is consistent with results from an earlier study using a shorter period of the ELSA sample [23]. Similarly, the associations with health behaviours such as levels of physical exercise and smoking are consistent in the two studies. These behaviours regulate trajectories in comparable ways in both sexes. Our findings extend their results by including comorbidities, enabling net associations with socio-economic factors to be recovered.

\section{Conclusions}

The trajectories of allostatic load in later life show distinct signatures for males and females. To uncover them not only is it necessary to use longitudinal data but also to account for attrition. With these done, both trajectories show clear social gradients in physiological wear and tear for an extended period in later life. Efforts to reduce these gradients earlier may yield fruit in later life by lightening the allostatic load, thus giving a healthier ageing experience to an increasingly large proportion of the population.

\section{Appendix 1}

Table 3 Models of age trajectories of allostatic load, coefficients and standard errors: main and interaction models. Source ELSA Wave 2, 4 and 6 (2004-2012). The Allostatic load score was calculated based on Read and Grundy (2014) [23]

\begin{tabular}{lll}
\hline & Main & Interaction \\
\hline Age & $0.036 \pm 0.001^{* * *}$ & $0.032 \pm 0.001^{* * *}$ \\
Sex, Female & $-0.066 \pm 0.018^{* * *}$ & $-0.451 \pm 0.126^{* * *}$ \\
Age* gender & & $0.005 \pm 0.001^{* * *}$ \\
Married/cohabit & $-0.027 \pm 0.019$ & $-0.02 \pm 0.019$ \\
Middle wealth & $-0.16 \pm 0.018^{* * *}$ & $-0.159 \pm 0.018^{* * *}$ \\
Wealthiest & $-0.304 \pm 0.02^{* * *}$ & $-0.303 \pm 0.02^{* * *}$ \\
High school & $-0.086 \pm 0.022^{* * *}$ & $-0.083 \pm 0.022^{* * *}$ \\
Some college & $-0.164 \pm 0.025^{* * *}$ & $-0.163 \pm 0.025^{* * *}$ \\
Num. comorbidities & $0.389 \pm 0.008^{* * *}$ & $0.39 \pm 0.008^{* * *}$ \\
Current smoker & $0.125 \pm 0.025^{* * *}$ & $0.126 \pm 0.025^{* * *}$ \\
Past smoker & $0.004 \pm 0.032$ & $0.003 \pm 0.032$ \\
Drink > 5 days/week & $-0.102 \pm 0.016^{* * *}$ & $-0.102 \pm 0.016^{* * *}$ \\
Vigorous exercise & $-0.2 \pm 0.017^{* * *}$ & $-0.201 \pm 0.017^{* * *}$ \\
Constant & $-0.388 \pm 0.077^{* * *}$ & $-0.185 \pm 0.102$ \\
\hline Note: Sig.** & $: \% \%$ or &
\end{tabular}

Note: Sig.: ${ }^{*}=10 \%$ or less; ${ }^{* *}: 5 \%$ or less; ${ }^{* *}: 1 \%$ or less 


\section{Appendix 2}

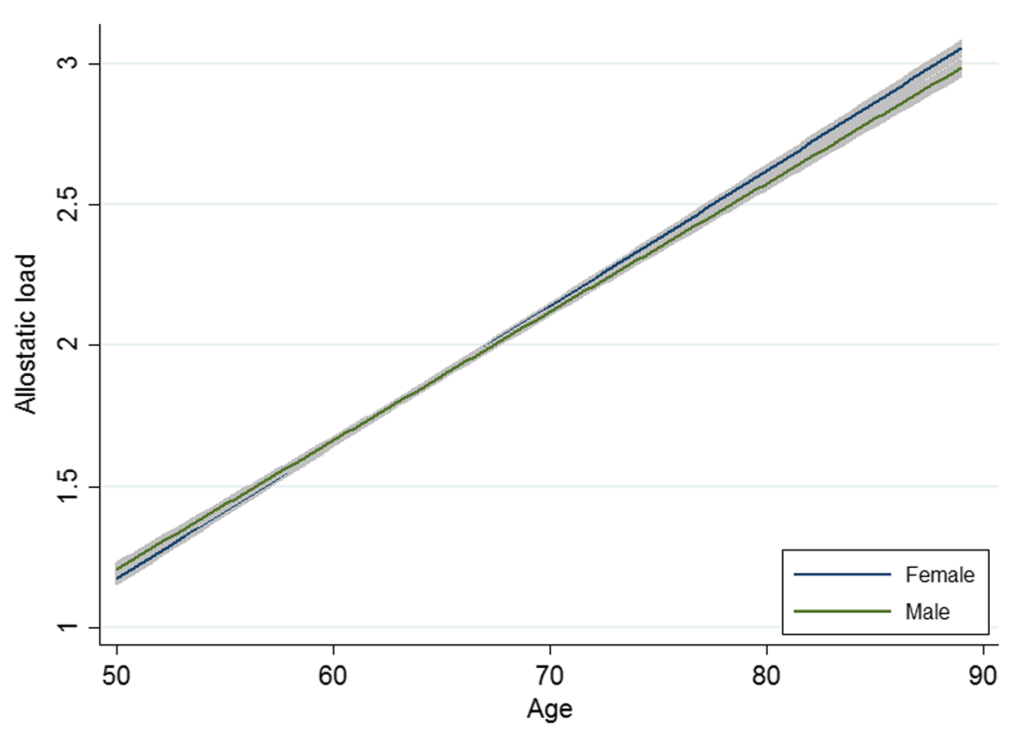

Fig. 4 Predicted trajectories of allostatic load for females and males. Source ELSA 2004-2013. The Allostatic load score was calculated based on Read and Grundy (2014)

\section{Appendix 3}

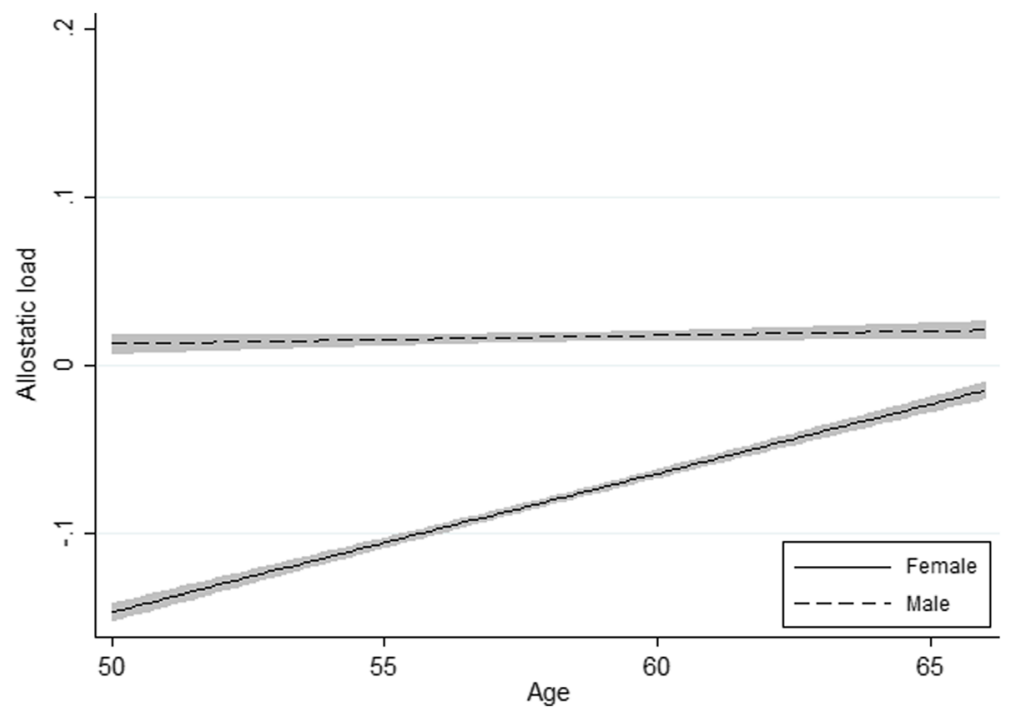

Fig. 5 Predicted trajectories of allostatic load among post-war cohort for females and males. Source ELSA 2004-2013 


\section{Appendix 4}

Table 4 Models of age trajectories of allostatic load, coefficients and standard errors: main and interaction models. Source HRS wave 8-11 (2006-2012) and ELSA Wave 2, 4 and 6 (2004-2012)

\begin{tabular}{|c|c|c|c|c|}
\hline & HRS & & ELSA & \\
\hline & Main & Interaction & Main & Interaction \\
\hline Age & $0.003 \pm 0.000^{* * *}$ & $0.001 \pm 0.000^{* * *}$ & $-0.000 \pm 0.000$ & $-0.002 \pm 0.000^{* * *}$ \\
\hline Sex, Female & $-0.071 \pm 0.011^{* * *}$ & $-0.226 \pm 0.048^{* * *}$ & $-0.110 \pm 0.012^{* * *}$ & $-0.408 \pm 0.061^{* * *}$ \\
\hline Age $^{*}$ gender & & $0.002 \pm 0.000^{* * *}$ & & $0.004 \pm 0.000^{* * *}$ \\
\hline Married/cohabit & $-0.024 \pm 0.008^{* * *}$ & $-0.020 \pm 0.008^{* *}$ & $-0.008 \pm 0.009$ & $-0.003 \pm 0.009$ \\
\hline Middle wealth & $-0.045 \pm 0.008^{* * *}$ & $-0.044 \pm 0.008^{* * *}$ & $-0.040 \pm 0.008^{* * *}$ & $-0.040 \pm 0.008^{* * *}$ \\
\hline Wealthiest & $-0.070 \pm 0.009^{* * *}$ & $-0.069 \pm 0.009^{* * *}$ & $-0.083 \pm 0.009^{* * *}$ & $-0.082 \pm 0.009^{* * *}$ \\
\hline High school & $-0.006 \pm 0.011$ & $-0.008 \pm 0.011$ & $-0.054 \pm 0.011^{* * *}$ & $-0.051 \pm 0.011^{* * *}$ \\
\hline Some college & $-0.050 \pm 0.010^{* * *}$ & $-0.050 \pm 0.010^{* * *}$ & $-0.097 \pm 0.012^{* * *}$ & $-0.096 \pm 0.012^{* * *}$ \\
\hline Num. comorbidities & $0.093 \pm 0.003^{* * *}$ & $0.094 \pm 0.003^{* * *}$ & $0.033 \pm 0.003^{* * *}$ & $-0.033 \pm 0.003^{* * *}$ \\
\hline Current smoker & $-0.031 \pm 0.011^{* * *}$ & $-0.030 \pm 0.011^{* *}$ & $-0.006 \pm 0.012$ & $-0.006 \pm 0.012$ \\
\hline Past smoker & $0.005 \pm 0.007$ & $0.007 \pm 0.007$ & $0.093 \pm 0.014^{* * *}$ & $0.092 \pm 0.014^{* * *}$ \\
\hline Drink $>5$ days/week & $-0.008 \pm 0.011$ & $-0.008 \pm 0.011$ & $-0.015 \pm 0.007^{* *}$ & $-0.015 \pm 0.007^{* *}$ \\
\hline Vigorous exercise & $-0.076 \pm 0.007^{* * *}$ & $-0.076 \pm 0.007^{* * *}$ & $-0.038 \pm 0.008^{* * *}$ & $-0.039 \pm 0.008^{* * *}$ \\
\hline Height & $0.216 \pm 0.052^{* * *}$ & $0.218 \pm 0.005^{* * *}$ & $-0.002 \pm 0.000^{* * *}$ & $-0.002 \pm 0.000^{* * *}$ \\
\hline Taking prescribed medication & $-0.007 \pm 0.022$ & $-0.008 \pm 0.022$ & & \\
\hline Taking medication for hypertension & & & $0.051 \pm 0.008^{* * *}$ & $0.050 \pm 0.008^{* * *}$ \\
\hline Taking medication for hyperlipidaemia & & & $0.050 \pm 0.009^{* * *}$ & $0.050 \pm 0.009^{* * *}$ \\
\hline Taking medication for diabetes mellitus & & & $0.207 \pm 0.016^{* * *}$ & $0.209 \pm 0.016^{* * *}$ \\
\hline Constant & $-0.557 \pm 0.102^{* * *}$ & $-0.476 \pm 0.104^{* * *}$ & $0.464 \pm 0.129^{* * *}$ & $0.616 \pm 0.132^{* * *}$ \\
\hline
\end{tabular}

Note: Sig.: ${ }^{*}=10 \%$ or less; ${ }^{* *}=5 \%$ or less; ${ }^{* * *}=1 \%$ or less

\section{Abbreviations}

BMI: Body Mass Index; CRP: C-Reactive Protein; ELSA: English Longitudinal Study of Ageing; HRS: Health and Retirement Study; UK: United Kingdom; US: United States

\section{Acknowledgments \\ No acknowledgment.}

\section{Funding}

This work was supported by grants from the Medical Research Council and Economic \& Social Research Council (grant no. G1001375/1), the National Institute of Health Research (grant no. ES/L001772/1) and the European Union's Horizon 2020 Research and Innovation Programme (grant no. 668648) to Gindo Tampubolon. Asri Maharani was supported by SENSE-Cog project, European Union's Horizon 2020 research and innovation programme under grant agreement No 668648.

\section{Availability of data and materials}

The HRS data can be accessed from the HRS website (http://

hrsonline.isr.umich.edu/), while ELSA data are freely available from the UK

Data Archive (www.data-archive.ac.uk) as study number 5050

\section{Authors' contributions}

GT designed the study. GT and AM analysed the data and wrote the manuscript. All authors read and approved the final manuscript.

\section{Competing interests}

The authors declare that they have no competing interests.

\section{Ethics approval and consent to participate}

Ethical approval for all the HRS waves was granted from the University of Michigan's Institutional Review Board (IRB) [44]. Collection and production of ELSA data comply with the requirements of the National Research and Ethics Committee of the UK National Health Service (www.nres.nhs.uk) [36]. The University's institutional review board has approved this study in its use of publicly available anonymised secondary data.

Ethical review for this study has been granted by the University of Manchester Institutional Review Board.

\section{Consent for publication}

Not applicable.

\section{Publisher's Note}

Springer Nature remains neutral with regard to jurisdictional claims in published maps and institutional affiliations.

\section{Author details}

${ }^{1}$ Sociology and Cathie Marsh Institute for Social Research, University of Manchester, Humanities Bridgeford Street Building, Oxford Road, Manchester M13 9PL, UK. ²Division of Neuroscience and Experimental Psychology, School of Biological Sciences, Faculty of Biology, Medicine and Health, University of Manchester, Manchester Academic Health Science Centre, Manchester M13 $9 \mathrm{PL}, \mathrm{UK}$

Received: 4 January 2018 Accepted: 10 October 2018 Published online: 23 October 2018

\section{References}

1. Mathers CD, Loncar D. Projections of global mortality and burden of disease from 2002 to 2030. PLoS Med. 2006;3(11):e442. 
2. Office of National Statistics. Statistical bulletin: health state life expectancies by national deprivation deciles, England and Wales: 2014 to 2016. 2018.

3. National Center for Health Statistics. National Vital Statistics Reports: United States Life Tables 2014. 2017.

4. Rieker PP, Bird CE. Rethinking gender differences in health: why we need to integrate social and biological perspectives. J Gerontol Ser B Psychol Sci Soc Sci. 2005;60:S40-7.

5. Hageman PA, Leibowitz JM, Blanke D. Age and gender effects on postural control measures. Arch Phys Med Rehabil. 1995;76(10):961-5.

6. Wolfson L, Whipple R, Dreby CA, Amerman P, Nashner L. Gender differences in the balance of healthy elderly as demonstrated by dynamic posturography. J Gerontol. 1994;49(4):M160-7.

7. Musselman K, Brouwer B. Gender-related differences in physical performance among seniors. J Aging Phys Act. 2005;13(3):239-53.

8. Colledge NR, Cantley P, Peaston I, Brash H, Lewis S, Wilson JA. Ageing and balance: the measurement of spontaneous sway by posturography. Gerontology. 1994;40(5):273-8.

9. Prudham D, Evans JG. Factors associated with falls in the elderly: a community study. Age Ageing. 1981;10(3):141-6.

10. Leveille SG, Penninx BW, Melzer D, Izmirlian G, Guralnik JM. Sex differences in the prevalence of mobility disability in old age: the dynamics of incidence, recovery, and mortality J Gerontol Series B, 2000. 55(1): S41-S50.

11. Murtagh KN, Hubert HB. Gender differences in physical disability among an elderly cohort. Am J Public Health. 2004;94(8):1406-11.

12. Vogel JA, Patton JF, Mello RP, Daniels WL. An analysis of aerobic capacity in a large United States population. J Appl Physiol. 1986;60(2):494-500.

13. Caspersen CJ, Pereira MA, Curran KM. Changes in physical activity patterns in the United States, by sex and cross-sectional age. Med Sci Sports Exerc. 2000;32(9):1601-9.

14. Heyward VH, Wagner DR. Applied body composition assessment. Champaign: Human Kinetics; 2004.

15. Yang Y, Kozloski M. Sex differences in age trajectories of physiological dysregulation: inflammation, metabolic syndrome, and allostatic load. J Gerontol A Biol Sci Med Sci. 2011;66(5):493-500.

16. Seeman TE, McEwen BS, Rowe JW, Singer BH. Allostatic load as a marker of cumulative biological risk: MacArthur studies of successful aging. Proc Natl Acad Sci. 2001;98(8):4770-5.

17. Seeman TE, Epel E, Gruenewald T, Karlamangla A, BS ME. Socio-economic differentials in peripheral biology: cumulative allostatic load. Ann N Y Acad Sci. 2010;1186(1):223-39.

18. Seeman TE, Singer BH, Rowe JW, Horwitz RI, BS ME. Price of adaptation-allostatic load and its health consequences: MacArthur studies of successful aging. Arch Intern Med. 1997;157(19):2259-68.

19. McEwen BS. Protective and damaging effects of stress mediators. N Engl J Med. 1998;338(3):171-9.

20. Seeman T. How do others get under our skin? Social relationships and health. 2001.

21. McEwen BS, Stellar E. Stress and the individual: mechanisms leading to disease. Arch Intern Med. 1993;153(18):2093-101.

22. Gruenewald TL, Karlamangla AS, Hu P, Stein-Merkin S, Crandall C, Koretz B, Seeman TE. History of socioeconomic disadvantage and allostatic load in later life. Soc Sci Med. 2012;74(1):75-83.

23. Read S, Grundy E. Allostatic load and health in the older population of England: a crossed-lagged analysis. Psychosom Med. 2014;76(7):490.

24. Hardy SE, Allore H, Studenski SA. Missing data: a special challenge in aging research. J Am Geriatr Soc. 2009;57(4):722-9.

25. Tampubolon G. Delineating the third age: joint models of older people's quality of life and attrition in Britain 2002-2010. Aging Ment Health. 2015;19(7):576-83.

26. Tampubolon G. Cognitive ageing in Great Britain in the new century: cohort differences in episodic memory. PLoS One. 2015;10(12):e0144907.

27. Graham PL, Ryan LM, Luszcz MA. Joint modelling of survival and cognitive decline in the Australian longitudinal study of ageing. J R Stat Soc: Ser C: Appl Stat. 2011;60(2):221-38.

28. Tampubolon $\mathrm{G}$. Trajectories of the healthy ageing phenotype among middle-aged and older Britons, 2004-2013. Maturitas. 2016;88:9-15.

29. Newman AB. An overview of the design, implementation, and analyses of longitudinal studies on aging. J Am Geriatr Soc. 2010;58:S287-91.

30. Ryff CD, Singer BH, Wing E, Love GD. Elective affinities and uninvited agonies. In: Emotion, social relationships, and health; 2001. p. 133-75.

31. Ryff CD, Singer BH. Emotion, Social Relationships, and Health. Oxford University Press; 2001.
32. Tampubolon G, Maharani A. When did old age stop being depressing? Depression trajectories of older Americans and Britons 2002-2012. Am J Geriatr Psychiatry. 2017;25(11):1187-95.

33. Tampubolon G, Maharani A. Depression trajectories of older Americans and Britons 2002-2013;2012: a rejoinder and a Hope. Am J Geriatr Psychiatry. 2017;25(11). https://doi.org/10.1016/j.jagp.2017.07.010.

34. Tampubolon G. Could cohort composition be driving this? Re: Temporal trend in dementia incidence since 2002 and projections for prevalence in England and Wales to 2040: modelling study. BMJ. 2017;358:j2856.

35. Sonnega A, Weir D. The health and retirement study: a public data resource for research on aging. Open Health Data. 2014;2(1).

36. Marmot M, Oldfield Z, Clemens S, Blake M, Phelps A, Nazroo J, Steptoe A, Rogers N, Bank J. English Longitudinal Study of Ageing: Waves 0-6, 1998 2013. Secondary English Longitudinal Study of Ageing: Waves 0-6, 1998. 2013: 2015.

37. Stephan Y, Sutin AR, Martina L, Antonio T. Allostatic load and personality: a 4-year longitudinal study. Psychosom Med. 2016;78(3):302-10.

38. Wilkinson RG, Marmot M. Social determinants of health: The solid facts: World Health Organization; 2003.

39. Marmot M. The health gap: The challenge of an unequal world. 2015: Bloomsbury Publishing.

40. Skelton D, Young A, Walker A, Hoinville E. Physical activity in later life: Further analysis of the Allied Dunbar national fitness survey and the Health Educ Authority national survey of activity and health. London: Health Educ Authority; 1999.

41. Rabbitt $P$, Diggle $P$, Smith D, Holland F, Mc Innes L. Identifying and separating the effects of practice and of cognitive ageing during a large longitudinal study of elderly community residents. Neuropsychologia. 2001; 39(5):532-43.

42. Karlamangla AS, Singer BH, BS ME, Rowe JW, Seeman TE. Allostatic load as a predictor of functional decline: MacArthur studies of successful aging. J Clin Epidemiol. 2002;55(7):696-710.

43. Singh-Manoux A, Kivimaki M, Glymour MM, Elbaz A, Berr C, Ebmeier KP, Ferrie JE, Dugravot A. Timing of onset of cognitive decline: results from Whitehall II prospective cohort study. BMJ. 2012;344:d7622.

44. Sonnega A, Faul JD, Ofstedal MB, Langa KM, Phillips JWR, Weir DR. Cohort profile: the health and retirement study (HRS). Int J Epidemiol. 2014;43(2):576-85.

Ready to submit your research? Choose BMC and benefit from:

- fast, convenient online submission

- thorough peer review by experienced researchers in your field

- rapid publication on acceptance

- support for research data, including large and complex data types

- gold Open Access which fosters wider collaboration and increased citations

- maximum visibility for your research: over $100 \mathrm{M}$ website views per year

At BMC, research is always in progress.

Learn more biomedcentral.com/submissions 